\title{
Acid-Labile Subunit (ALS) Measurements in Children
}

\author{
Atsuko NIMURA, Noriyuki KATSUMATA, Reiko HORIKAWA, Ayako TANAE and \\ TOSHIAKI TANAKA
}

\begin{abstract}
Department of Endocrinology and Metabolism, National Children's Medical Research Center and Division of Endocrinology and Metabolism, National Children's Hospital, Tokyo 154-8509, Japan
\end{abstract}

\begin{abstract}
Almost all of the serum IGFs are found in a ternary complex composed of IGF, IGFBP-3 and acid-labile subunit (ALS). It was reported that ALS levels were age- and sex-dependent. In the present study we measured serum ALS levels in 264 normal children (145 boys and 119 girls) aged from 5 days to 16 years, and 15 patients with growth hormone deficiency (GHD) aged from 11 months to 13 years. Serum ALS levels increased during childhood, and reached peak values in mid to late puberty. ALS levels reached their highest levels 2 years earlier in girls than in boys. Serum ALS levels were significantly correleted with serum IGF-I levels and IGFBP-3 levels. Serum ALS levels were below -2SD in 6 out of 7 children with complate GHD (CGHD), while serum ALS levels were below -2 SD in 1 out of 8 patients with partial GHD (PGHD). These results indicate that serum ALS levels are regulated by $\mathrm{GH}$, and that the measurement of ALS is useful for the diagnosis of CGHD in children.
\end{abstract}

Key words: Acid-labile subunit (ALS), IGF, IGFBP, Growth hormone deficiency

(Endocrine Journal 47: S111-S114, 2000)

CIRCULATING insulin-like growth factor I and II (IGF-I and IGF-II) are predominantly found in a ternary complex composed of IGF, IGF-binding protein-3 (IGFBP-3) and acid-labile subunit (ALS) [1]. It has been reported that serum levels of ALS were lowest in neonates, rose steadily to peak values in mid to late puberty, and slowly declined throughout adult life $[2,3]$. But there are only a few reports on serum ALS levels in adult patients with growth hormone deficiency (GHD) [2-4], and there exist no reports on serum ALS levels in children with GHD.

In the present study we measured serum levels of ALS in 264 normal children and 15 patients with GHD to elucidate the clinical utility of ALS measurements in children.

Correspondence to: Dr. Atsuko NIMURA, Department of Endocrinology and Metabolism, National Children's Medical Research Center, 3-35-31 Taishido, Setagaya-ku, Tokyo 1548509, Japan

\section{Subjects and Methods}

Subjects were 264 healthy children and 15 patients with GHD before receiving any treatment. The healthy children were composed of 145 boys aged from 5 days to 16 years and 119 girls aged from 1 year to 16 years. The patients with GHD were aged from 11 months to 13 years, and composed of 13 boys and 2 girls, 7 patients with complete GHD (CGHD) and 8 patients with partial GHD (PGHD). Growth hormone deficiency was defined by the peak GH level obtained by at least two stimulation tests: for CGHD group, all GH peaks $<5 \mathrm{ng} / \mathrm{ml}$; for PGHD group, highest $\mathrm{GH}$ peak $>5 \mathrm{ng} / \mathrm{ml}$ but less than $10 \mathrm{ng} / \mathrm{ml}$. The CGHD group included 2 patients with hereditary isolated growth hormone deficiency type 1A (IGHD1A), who were aged 3 years and 4 years.

Serum levels of ALS were measured with an RIA kit (Bioclone Australia Pty., Limited, Marrickville, New South Wales, Australia). The serum levels of IGF-I and IGFBP-3 were measured by the specific RIA methods as previously reported $[5,6]$. 


\begin{abstract}
Results
ALS in normal children

Serum ALS levels increased during childhood, and reached peak values in mid to late puberty. ALS levels reached their highest levels 2 years earlier in girls than in boys (Fig. 1 and Table 1).
\end{abstract}

\section{Relations between ALS and IGF-I, IGFBP-3}

ALS was significantly correlated with IGF-I $(r=$ $0.783, \mathrm{p}<0.0001)$ and IGFBP-3 $(\mathrm{r}=0.832, \mathrm{p}<$ 0.0001) (Fig. 2).

\section{$A L S$ in GHD patients}

Serum ALS levels were below -2SD in 6 out of 7 patients with CGHD (Fig. 3). Serum ALS was undetectable in 2 patients with IGHD1A.

Serum ALS levels were below -2SD in 1 out of 8 patients with PGHD, while they were within the normal range in the rest (Fig. 3).

\section{Discussion}

It was reported that the production of ALS is GH-dependent in adults [2-4]. Furthermore GH was demonstrated to stimulate the transcription of the ALS gene through binding of STAT5a and STAT5b to a $\gamma$-interferon-activated sequence (GAS)-like ele-

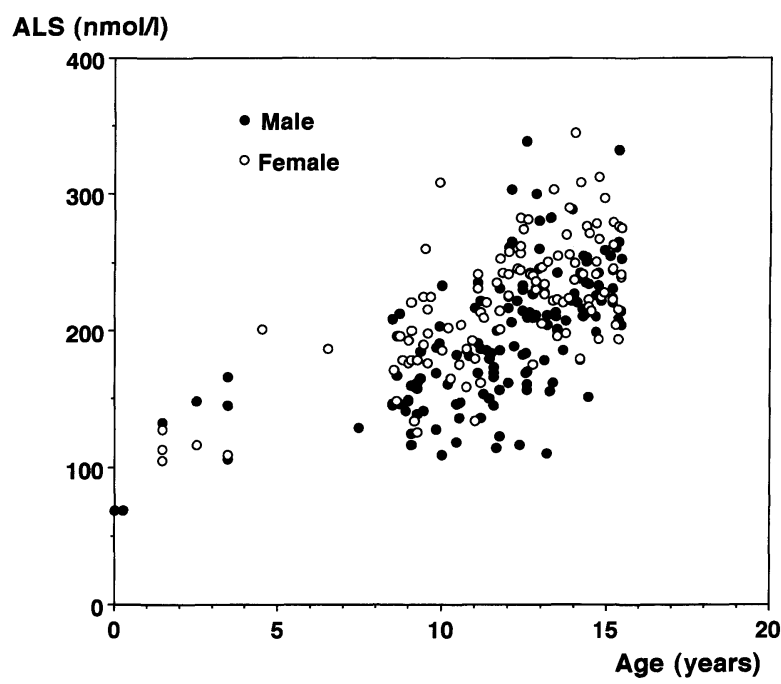

Fig. 1. Serum ALS levels in normal healthy children.

ment in its promoter region in liver cells [7]. Therefore it was expected that ALS measurements might be useful in the diagnosis of GHD in children. In order to investigate the diagnostic value of ALS in childhood, we needed to have valid normative data, so we determined serum ALS levels in 264 healthy children. Serum ALS levels increased during childhood, and reached peak values in mid to late puberty. ALS showed only a mild elevation in puberty, resembling IGFBP-3 [6], not IGF-I, which shows marked elevation in puberty [5]. These observations were consistent with previous reports $[2,3]$.

ALS levels were closely related to IGF-I levels, and more closely related to IGFBP-3 levels in serum samples from normal healthy children. This may

Table 1. Normal ranges for serum ALS levels.

\begin{tabular}{cccccc}
\hline $\begin{array}{c}\text { Age } \\
\text { (years) }\end{array}$ & Sex & N & $\begin{array}{c}\text { Mean } \pm \text { SD } \\
(\mathrm{nmol} / \mathrm{l})\end{array}$ & $\begin{array}{c}\text { Mean-2SD } \\
(\mathrm{nmol} / \mathrm{l})\end{array}$ & $\begin{array}{c}\text { Mean+2SD } \\
(\mathrm{nmol} / \mathrm{l})\end{array}$ \\
\hline $0-2$ & M \& F & 9 & $111.31 \pm 27.35$ & 56.59 & 166.02 \\
$3-5$ & M \& F & 6 & $136.58 \pm 42.02$ & 52.52 & 220.63 \\
$6-8$ & M \& F & 15 & $167.82 \pm 26.94$ & 113.92 & 221.70 \\
& M & 25 & $157.44 \pm 29.63$ & 98.17 & 216.70 \\
$9-10$ & F & 25 & $194.44 \pm 37.12$ & 120.20 & 268.68 \\
& M & 52 & $200.09 \pm 47.82$ & 104.45 & 295.73 \\
$11-12$ & F & 32 & $231.31 \pm 33.27$ & 164.75 & 297.86 \\
& M & 38 & $216.23 \pm 35.60$ & 145.03 & 287.43 \\
$13-14$ & F & 38 & $246.05 \pm 36.97$ & 172.09 & 320.00 \\
& M & 12 & $239.75 \pm 36.73$ & 166.29 & 313.21 \\
& F & 12 & $242.00 \pm 28.74$ & 184.52 & 299.48 \\
\hline
\end{tabular}



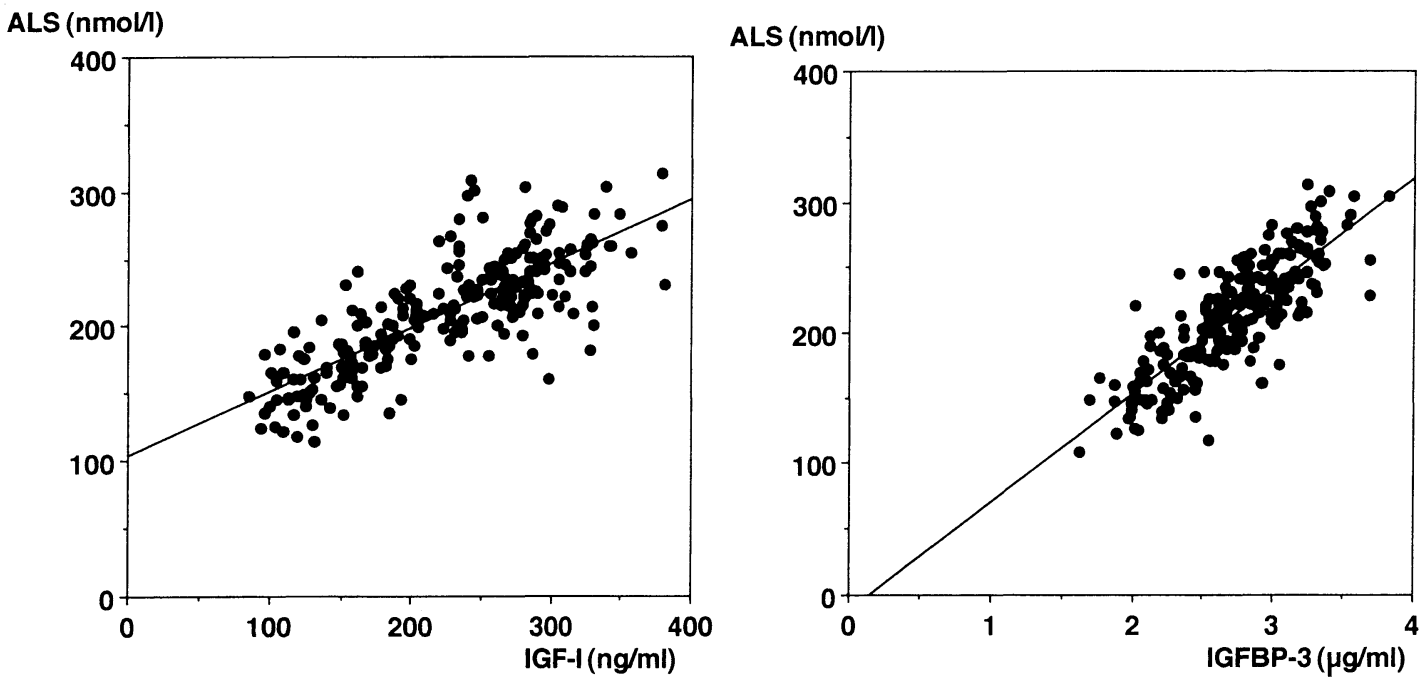

Fig. 2. Correlation between ALS and IGF-I, IGFBP-3 levels in sera from normal healthy children.

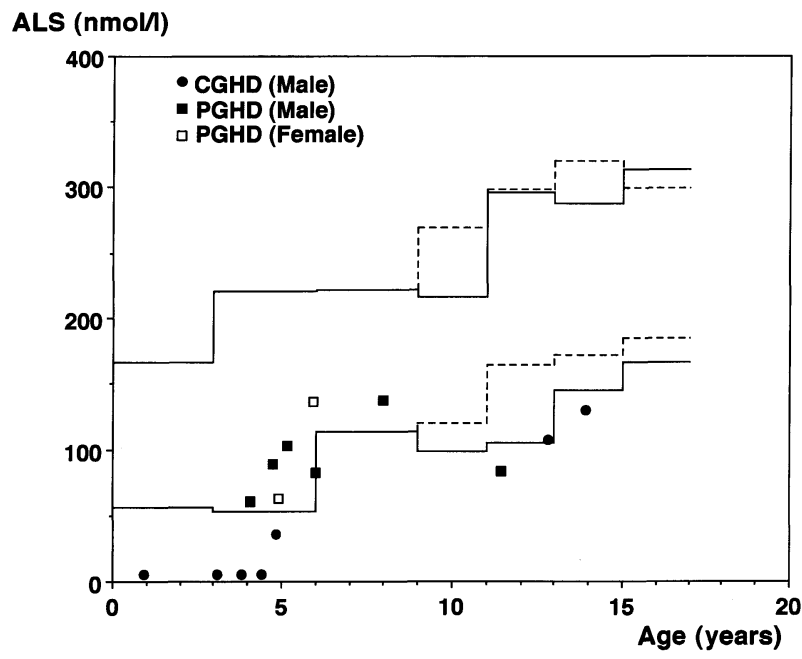

Fig. 3. Serum ALS levels in children with GHD. The solid lines indicate the normal ranges for children younger than 9 years and for male children older than 9 years. The interrupted lines indicate the normal ranges for female children older than 9 years.

suggest that ALS and IGFBP-3 are correlated in the liver or that all IGFBP-3 is bound to ALS through an IGF-dependent or independent mechanism and is rapidly cleared from the circulation in its unbound form. Whatever the mechanism underlying the cor- relation of the three components of the ternary complex is, they can be an independent indicator of GH secretory status.

Serum ALS levels were below -2SD in almost all children with CGHD. Noteworthily, serum ALS was undetectable in 2 patients with IGHD1A resulting from the deletion of the structural gene for $\mathrm{GH}$. These findings indicate that GH is essential to ALS synthesis in vivo, and that the ALS measurement is useful for the diagnosis of CGHD in children. Serum ALS levels were within in the normal range in many children with PGHD. This is also the case for IGF-I and IGFBP-3 measurements in children with PGHD [5, 6]. Further study is necessary to compare the sensitivity and the specificity of the ALS, IGF-I and IGFBP-3 measurements in the diagnosis of GHD, especially in the diagnosis of PGHD.

\section{Acknowledgments}

We are grateful to Cosmic Corp., Ltd. for the ALS measurement. This work was supported in part by a research grant from the Foundation for the Growth Science, Japan. 


\section{References}

1. Baxter RC (1994) Insulin-like growth factor binding protein in the human circulation: a review. Horm Res 42: 140-144.

2. Baxter RC (1990) Circulating levels and molecular distribution of the acid-labile $(\alpha)$ subunit of high molecular weight insulin-like growth factor binding protein complex. J Clin Endocrinol Metab 70: 13471353.

3. Juul A, Moller S, Mosfeldt-Laursen E, Rsmussen MH, ScheikeT, Pedersen SA, Kastrup KW, Yu H, Mistry J, Rasmussen S, Muller J, Henriksen J, Skakkebaek (1998) The acid-labile subunit of human ternary insulin-like growth factor binding protein complex in serum: hepatosplanchnic release, diurnal variation, circulating concentrations in healthy subjects, and diagnostic use in patients with growth hormone deficiency. J Clin Endocrinol Metab 83: 44084415.

4. Khosravi MJ, Diamandi A, Mistry J, Krishna RG, Khare A (1997) Acid-labile subunit of human insulin-like growth factor-binding protein complex: measurement, molecular, and clinical evaluation. $J$ Clin Endocrinol Metab 1997; 82: 3944-351.

5. Suwa S, Katsumata N, Maesaka H, Tokuhiro E, Yokoya S (1988) Serum insulin-like growth factor I (somatomedin-C) level in normal subjects from infancy to adulthood, pituitary dwarfs and normal variant short children. Endocrinol Japon 35: 857864.

6. Katsumata N, Tanaka T, Hasegawa Y, Tachibana K, Yokoya S, Hizuka N, Teramoto A, Suwa S, Irie M (1997) Basic and clinical evaluation of serum insulinlike growth factor binding protein-3 (IGFBP-3) measurement by a radioimmunoassay kit. Clin Endocrinol (Tokyo) 45: 509-517 (in Japanese).

7. Ooi GT, Hurst KR, Poy MN, Rechler MM, BoisclairYR (1998) Binding of STAT5a and STAT5b to a single element resembling a $\gamma$-interferon-activated sequence mediates the growth hormone induction of the mouse acid -labile subunit promoter in liver cells. Mol Endocrinol 12: 657-687. 